www.jmscr.igmpublication.org Impact Factor 5.244

Index Copernicus Value: 83.27 ISSN (e)-2347-176x ISSN (p) 2455-0450 crossref DOI: _https://dx.doi.org/10.18535/jmscr/v4i12.69

\title{
Apolipoproteins and Their Correlation with Some Early Markers of Vascular Disease in Subjects at Different Risk Categories
}

\author{
Authors \\ Muhammad Tawfik khattab, Ibrahim Naguib Al Ebrashy, Dawlat Ibrahim Salem*, \\ Ahmad Amin Heikal \& Mohamed Mohamed Ahmad Ibrahim \\ Internal Medicine, Medical Biochemistry* Departments, Cairo University
}

\begin{abstract}
Objective: This study was conducted to study the correlation between plasma apolipoproteins (Apo A-1, $A p o B$ \& the ratio of ApoB to ApoA-1) and carotid intima-media thickness in subjects at different degrees of risk for cardiovascular disease.

Material \& Methods: The study included 80 subjects selected from the employee of kasr Al aini Shool of medicine. All subjects were subjected to clinical assessment \& laboratory investigations including lipid profile, apolipoproteins $B \& A 1, C R P \&$ microalbuminurea. Finally CIMT was performed to all our subjects.

Results: Our results showed statistically significant negative correlation between apo- Al versus Framingham, SCORE system \& Number of risks, and significant positive correlation with HDL. There was also statistically significant positive correlation between apo-B versus Framingham, SCORE system, Number of risks, cholesterol and LDL \& statistically significant positive correlation between Apo-B / Apo A1 versus Framingham, SCORE system, number of risks, total cholesterol, LDL and negative correlation to HDL. Our subjects who were positive with metabolic syndrome had higher CIMT, higher apo B, higher apoB/ apo A-1 ratio, lower apo-A compared to subjects without metabolic syndrome. There was also statistically significant positive correlation between carotid intima media thickness (cIMT) versus age, SBP, apo B, apo B/A-1, microalbuminuria and negatively correlated to apo A-1.

Conclusion: We conclude from the results in our study that the estimation of the apo B to apo A-1 ratio and the use of the number of risk factors as a score system for the estimation of cardiovascular risk show a strong association with CIMT which can be of significant importance in delineating vascular risk.

Key Words: apolipoprotein B, apolipoprotein A-1, atherosclerosis, CIMT, hsCRP.
\end{abstract}

\section{Introduction}

Metabolic syndrome contributes to the increase in the risk of cardiovascular disease, type 2 diabetes mellitus, and all cause mortality. It includes several metabolic, clinical \& pathophysiological factors such as: insulin resistance, visceral adiposity, atherogenic dyslipidemia, endothelial dysfunction, genetic susceptibility, elevated blood pressure, hypercoagulable state, and chronic stress. The main core of this syndrome is visceral adiposty and insulin resistance which are associated with chronic inflammation \& are characterized by the production of abnormal adipocytokines such as tumor necrosis factor $\alpha$, interleukin-1 (IL-1), IL-6, leptin, and adiponectin. The ultimate result will be the development of a 
proinflammatory state and a chronic subclinical vascular inflammation which modulates and results in the atherosclerotic processes. ${ }^{(1)}$

Atherosclerosis is an extremely complex phenomenon, and although many of the factors that predispose to this condition are well known on a population level, their interactions and their impact on each individual patient are very complex, if not impossible, to predict. ${ }^{(2)}$

Previous studies showed that inflammation contributes to both the onset and progression of atherosclerosis: actually, atherosclerosis is predominantly a chronic low-grade inflammatory disease of the vessel wall. ${ }^{(3)}$

Atherosclerosis increases the risk of coronary artery disease. Various markers that might better predict the risk of the latter have been identified including low level of Apolipoprotein A, high concentrations of Apo B, IDL, small dense LDL, oxidised LDL and lipoprotein (a). It has been stated that LDL particles differ substantially from one another in the amount of cholesterol they contain. This contributes to the constellation that total cholesterol and LDL-C are considered to some extent to be imprecise measures of the number of Apo B particles. Measuring Apo B, therefore, provides a direct estimate of the total number of atherogenic particles. ${ }^{(4)}$

Apolipoprotein B (Apo B) reflects the concentration of the total burden of potentially atherogenic lipoprotein particle. On the other hand Apolipoprotein A-I (Apo A-1) reflects the corresponding concentration of the antiatherogenic HDL. A growing body of evidence suggests that increased blood levels of Apo B, decreased apo A-1 and increased apo B / apo A- I ratio are more informative markers that predict cardiovascular atherosclerotic disease than traditional lipid profile ${ }^{(5)}$.

The rationale for developing and using a riskestimation system lies in the fact that in most people, atherosclerotic cardiovascular disease is the product of more than one risk factor. A combination of several seemingly modest factors may result in a much higher total risk than a single factor. Therefore, systems to estimate total risk as Framingham point score \& SCORE system have been developed ${ }^{(6)}$.

Carotid intima medial thickness (CIMT) is an independent predictor of cardiovascular risk (CV) risk and the presence of carotid plaque is a strong predictor of $\mathrm{CV}$ events and mortality ${ }^{(7)}$. B-mode ultrasonography is a relatively inexpensive, noninvasive, safe technique to evaluate the carotid arteries for plaque and to measure CIMT. The consensus statement from the American Society of Echocardiography recommends imaging the CIMT of the distal $1 \mathrm{~cm}$ of the far wall of each common carotid artery, as well as plaques of the extracranial carotid arteries, especially at the bifurcation and the internal carotid artery, because irrespective of CIMT, patients with carotid plaques are at high risk. ${ }^{(8)}$

A study done in 2014 by Lundberg \& colleagues confirmed that CIMT is considered as a general marker for atherosclerosis \& that it is related to the base line CIMT rather than the rate of change over 5 years. ${ }^{(9)}$

The measurement of markers of inflammation has been proposed as a method to improve global cardiovascular risk prediction. Among them are markers of systemic inflammation produced in the liver, such as CRP. When determined with a high sensitivity test, CRP is an independent predictor of future cardiovascular events and adds prognostic information to lipid screening. ${ }^{(10)}$

The aim of this research is to study the correlation between plasma apolipoproteins (Apo A-1, ApoB, the ratio of ApoB to ApoA-1) and carotid intimamedia thickness in subjects at different degrees of risk for cardiovascular disease.

Subjects: The study was done over 80 subjects selected from the employee of kasr Al aini Shool of medicine after an informed consent with the ethical regulation of conducting the study on human participants. Subjects had different risk factors of atherosclerosis as sex, age, obesity, smoking, hypertension, diabetes mellitus and dyslipidemia. 
Methods

All subjects were subjected to the following:

1. History and clinical examination .

2. Anthropometric measurements including height, weight and body mass index

3. Resting ECG. (all subjects had no evidence of ischemic heart disease)

4. Laboratory investigations:

a) Blood glucose tests.

b) Test for microalbuminuria: the measurement of microalbuminurea was done by the Micro-Albumin Quantitative test system which is a solid phase enzymelinked immunosorbant assay (ELISA). The wells are coated with specific albumin.

c) High sensitivity CRP: The hsCRP ELISA is based on the principle of a solid phase enzyme-linked immunosorbent assay.

d) Lipid profile including total cholesterol, triglycerides, HDL, LDL. After 12 hours fasting. The LDL was calculated by friedewald formula as follow: $\mathrm{LDL}=\mathrm{TC}$ (HDL+ (TG/5)) (11).

e) Plasma apolipoprotein A1 apolipoprotein B and Apo B / ApoA-1 ratio is calculated by dividing apo $\mathrm{B}$ on apo A-I.

Measurement of Apo B: By the Assay Max Human Apolipoprotein B ELISA Kit Catalog Number EA7001-1. The AssayMax Human Apo B ELISA (Enzyme-Linked Immunosorbent Assay) kit is designed for detection of human Apo $B$ in plasma, serum, urine, and cell culture samples. This assay employs a quantitative sandwich enzyme immunoassay technique that measures human Apo B in less than 4 hours.

Measurement of apo A-I: By the Assay Max Human Apolipoprotein A-I ELISA Kit Catalog Number EA5201-1. The Assay Max Human Apo A-1 ELISA (Enzyme-Linked Immunosorbent Assay) kit is designed for detection of human Apo A-1 in plasma, serum and cell culture supernatants. This assay employs a quantitative competitive enzyme immunoassay technique that measures human Apo A-1 in less than 3 hours.
5. Measurement of intima media thickness of common carotid artery using colour duplex ultrasound (ATL HDI model 5000) with probe of $7.4 \mathrm{MHz}$ frequencies by taking longitudinal section of the far wall of the common carotid artery, according to Geuroulakos protocol, who described a pattern of lines that could be seen on ultrasonic images of the arterial wall and called them I and $\mathrm{M}$ lines that make up the IM complex ${ }^{(12)}$. The IMT was measured at the end-diastole at 3 different points in the far wall of the common carotid artery 10 $\mathrm{mm}$ from carotid bifurction on each side and the mean of the maximum IMT was taken into consideration for calculation in the results. Intima-media thickness was measured from the leading edge of the lumen-intima interface of the far wall to the leading edge of the media-adventitia interface of the far wall. Carotid plaques were excluded in the calculation for the mamaximum IMT ${ }^{(13)}$.

Classifying subjects into those having metabolic syndrome and those without. According to the new harmonized International Diabetes Federation criteria for metabolic syndrome, any three of the following five criteria are considered to have the metabolic syndrome: Increased waist circumfer-ence ( $\geq 94 \mathrm{~cm}$ for men and $\geq 80 \mathrm{~cm}$ for women), High triglycerides ( $\geq 150 \mathrm{mg} / \mathrm{dL})$, Reduced HDL cholesterol $(<40$ $\mathrm{mg} / \mathrm{dL}$ for males and $<50 \mathrm{mg} / \mathrm{dL}$ for females), Elevated blood pressure (Systolic $\geq 130 \mathrm{~mm} \mathrm{Hg}$ and/or diastolic $\geq 85 \mathrm{~mm} \mathrm{Hg}$ ) \& increased fasting glucose $\geq 100 \mathrm{mg} / \mathrm{dL}^{\text {(14) }}$.

Risk stratification of subjects according to the number of risk factors.

The followings are the number of risk factors considered in our study:

1. Sex: male gender.

2. Age: above 50 years.

3. Obesity: body mass index $\geq 30(\mathrm{~kg} / \mathrm{m} 2)$.

4. Current Smoking. 
5. Diabetes: known or discovered to be diabetic,diabetes mellitus was defined as fasting blood glucose $\geq 126 \mathrm{mg} / \mathrm{dL}$ and/or post-prandial blood glucose $\geq 200 \mathrm{mg} / \mathrm{dL}$

6. Hypertensive: known or discovered to be hypertensive ( $\geq 140 / 90)$.

7. Known dyslipidemic on statins.

8. Total cholesterol $>200 \mathrm{mg} / \mathrm{dl}$.

9. Triglycerides $>150 \mathrm{mg} / \mathrm{dl}$.

10. $\mathrm{LDL}>100 \mathrm{mg} / \mathrm{dl}$.

11. HDL $<40 \mathrm{mg} / \mathrm{dl}$ in male and $<50 \mathrm{mg} / \mathrm{dl}$ in female.

Risk stratification of subjects using Framingham point score system (High risk > $20 \%$, intermediate risk $10-20 \%$, low risk $<10 \%$ ). (15).

Risk stratification of subjects using the SCORE system:

(very high risk, high risk, intermediate risk, low risk ).(16)

\section{Statistical Analysis}

Pre-coded data was statistically analyzed by the Statistical Package of Social Science Software program (SPSS), version 21.Data was summarized using frequency and percentage for qualitative data or mean and standard deviation for quantitative ones. Comparison between groups was performed using Chi square test to compare qualitative variables between groups \& Mann Whitney test was used to compare two groups as regard quantitative variable in non parametric data (SD > 50\%mean). Spearman correlation coefficient was calculated to clarify the association between ordinal and quantitative variables. Linear regression using stepwise technique was used to find out the effect of different independent predictors to certain dependent ones.

\section{RESULTS}

Table 1: Description of qualitative variables of the study group

\begin{tabular}{|l|c|c|}
\hline Variables & Number & Percentage \\
\hline Gender & 28 & $35 \%$ \\
$\bullet \quad$ Male & 52 & $65 \%$ \\
\hline$\quad$ Female & 59 & $73.8 \%$ \\
Smoking Negative & 21 & $26.2 \%$ \\
$\bullet \quad$ Positive & 50 & $62.5 \%$ \\
\hline HTN (discovered or on treatement) & 30 & $37.5 \%$ \\
\hline DM ( discovered or on treatement) & 21 & $26.6 \%$ \\
\hline Dyslipidemia( discovered or on statins) & & \\
\hline
\end{tabular}

Table 2: Description of quantitative variables of the study group

\begin{tabular}{|l|c|c|}
\hline Variables & Mean \pm SD & Range \\
\hline Age (years) & $51 \pm 5$ & $39-59$ \\
\hline Body mass index(kg/m2) & $35 \pm 6$ & $24-54$ \\
\hline Waist circumference(cm) & $98 \pm 9$ & $78-118$ \\
\hline SBP(mmHg) & $144 \pm 8$ & $(110-185)$ \\
\hline DBP(mmHg) & $83 \pm 7$ & $(70-95)$ \\
\hline HBA1c/\%) & $6.6 \pm 1$ & $4.3-8.6$ \\
\hline Cholesterol (mg/dl) & $187 \pm 38$ & $117-315$ \\
\hline TG(mg/dl) & $153 \pm 84$ & $40-551$ \\
\hline HDL(mg/dl) & $34.6 \pm 11$ & $16-69$ \\
\hline LDL(mg/dl) & $121 \pm 34$ & $58-246$ \\
\hline Microalbuminuria (ug/ml) & $57 \pm 25$ & $30-120$ \\
\hline apo A-1(mg/dl) & $105 \pm 30$ & $50-135$ \\
\hline apo-B(mg/dl) & $135 \pm 21$ & $100-200$ \\
\hline apo-B /apo A-1 & $1.4 \pm 0.38$ & $0.65-2.63$ \\
\hline Carotid intima media thickness(mm) & $0.86 \pm 0.26$ & $0.4-1.6$ \\
\hline
\end{tabular}


Table 3: Classification of subjects as regards different risk estimation systems

\begin{tabular}{|c|c|c|}
\hline Risk estimation system & Number of subjects & Percentage of subjects \\
\hline $\begin{aligned} & \text { Framingham system } \\
& \text { - } \text { Low risk } \\
& \text { - } \text { Intermediate risk } \\
& \text { - } \text { High risk }\end{aligned}$ & $\begin{array}{l}31 \\
13 \\
36\end{array}$ & $\begin{array}{c}38.7 \% \\
16.3 \% \\
45 \%\end{array}$ \\
\hline $\begin{array}{cl}\text { SCORE system } \\
\qquad & \text { Low risk. } \\
\text { - } & \text { Interm.risk. } \\
\text { - } & \text { High risk. } \\
\text { - } & \text { Very high risk }\end{array}$ & $\begin{array}{c}20 \\
23 \\
7 \\
30\end{array}$ & $\begin{array}{c}25 \% \\
28.75 \% \\
8.75 \% \\
37.5 \%\end{array}$ \\
\hline $\begin{array}{cl}\text { Number of risks } \\
\text { - } & \text { Three risk factors } \\
\text { - } & \text { Four risk factors } \\
\text { - } & \text { Five risk factors } \\
\text { - } & \text { Sixth risk factors } \\
\text { - } & \text { Seven risk factors } \\
\text { - } & \text { Eight risk factors } \\
\text { - } & \text { Nine risk factors } \\
\text { - Ten risk factors }\end{array}$ & $\begin{array}{c}3 \\
10 \\
7 \\
22 \\
18 \\
11 \\
6 \\
3\end{array}$ & $\begin{array}{c}3.8 \% \\
12.5 \% \\
8.8 \% \\
27.4 \% \\
22.4 \% \\
13.8 \% \\
7.5 \% \\
3.8 \%\end{array}$ \\
\hline Subjects with Metabolic syndrome & 62 & $\mathbf{7 7 . 5 \%}$ \\
\hline Subjects without Metabolic syndrome & 18 & $22.5 \%$ \\
\hline
\end{tabular}

Table 4: Correlation between apo-A versus other variables

\begin{tabular}{|l|c|c|}
\hline Variables & \multicolumn{2}{|c|}{ apo A-1 } \\
& r & p \\
\hline Age & 0.14 & $>0.05$ \\
\hline BMI & 0.11 & $>0.05$ \\
\hline SBP & 0.17 & $>0.05$ \\
\hline DBP & 0.10 & $>0.05$ \\
\hline Framingham score & -0.30 & $<0.05 \mathrm{~S}^{*}$ \\
\hline SCORE System & -0.29 & $<0.05 \mathrm{~S}$ \\
\hline Number of risks & -0.37 & $<0.05 \mathrm{~S}$ \\
\hline hs-CRP & 0.12 & $>0.05$ \\
\hline HbA1c & 0.18 & $>0.05$ \\
\hline HDL & 0.31 & $<0.05 \mathrm{~S}$ \\
\hline
\end{tabular}

$\mathrm{S}^{*}$ :significant.

This table shows statistically significant negative

positive correlation with HDL by using correlcorrelation between apo- A1 versus Framingham, ation coefficient test. No significant correlation SCORE system, Number of risks, and significant was observerd as regard other variables.

Table 5: Correlation between APO-B versus different variables

\begin{tabular}{|l|c|c|}
\hline Variables & \multicolumn{2}{|c|}{ Apo B } \\
& r & p \\
\hline Age & 0.13 & $>0.05$ \\
\hline BMI & 0.01 & $>0.05$ \\
\hline SBP & 0.17 & $>0.05$ \\
\hline DBP & 0.12 & $>0.05$ \\
\hline Framingham score & 0.27 & $<0.05 \mathrm{~S}^{*}$ \\
\hline SCORE System & 0.25 & $<0.05 \mathrm{~S}$ \\
\hline Number of risks & 0.39 & $<0.05 \mathrm{~S}$ \\
\hline hs-CRP & 0.18 & $>0.05$ \\
\hline HbA1c & 0.13 & $>0.05$ \\
\hline Total cholesterol & 0.39 & $<0.05 \mathrm{~S}$ \\
\hline LDL & 0.37 & $<0.05 \mathrm{~S}$ \\
\hline
\end{tabular}

$\mathrm{S} *$ :significant. 
This table shows statistically significant positive correlation between apo-B versus Framingham, SCORE system, Number of risks, cholesterol and
LDL by using correlation coefficient test. No significant correlation as regard other variables.

Table 6: Correlation between apo-B/apo-A1 versus different variables

\begin{tabular}{|l|c|c|}
\hline Variables & \multicolumn{2}{|c|}{$\begin{array}{c}\text { APO-B /APO-A1 } \\
\text { r }\end{array}$} \\
\hline Age & 0.19 & $>0.05$ \\
\hline BMI & 0.09 & $>0.05$ \\
\hline SBP & 0.18 & $>0.05$ \\
\hline DBP & 0.16 & $>0.05$ \\
\hline Framingham score & 0.28 & $<0.05 \mathrm{~S}^{*}$ \\
\hline SCORE System & 0.35 & $<0.05 \mathrm{~S}$ \\
\hline Number of risks & 0.34 & $<0.05 \mathrm{~S}$ \\
\hline hs-CRP & 0.11 & $>0.05$ \\
\hline HbA1c & 0.10 & $>0.05$ \\
\hline Total cholesterol & 0.32 & $<0.05 \mathrm{~S}$ \\
\hline LDL & 0.31 & $<0.05 \mathrm{~S}$ \\
\hline HDL & -0.28 & $<0.05 \mathrm{~S}$ \\
\hline
\end{tabular}

S*: Significant.

This table shows statistically significant positive correlation between Apo-B / Apo A-1 versus Framingham, SCORE system, number of risks ,total cholesterol, LDL and negative correlation to HDL by using correlation coefficient test. No significant correlation as regard other variables.

Table 7: Comparison between cases who are positive and negative for the metabolic syndrome as regard CIMT, microlabuminuria and apo-A, apo- B and apo B/apo A-1

\begin{tabular}{|l|c|c|c|c|c|}
\hline Variables & Metabolic No & Syndrome yes & $\mathrm{t}$ & $\mathrm{P}$ & \\
\hline Microalbuminuria & $64+12$ & $51+18$ & 2.1 & $<0.05$ & $\mathrm{~S}^{*}$ \\
\hline CIMT & $0.62+0.16$ & $0.92+0.28$ & 4 & $<0.001$ & HS** \\
\hline Apo A-1 & $123+18$ & $99.9+31$ & 2.9 & $<0.05$ & $\mathrm{~S}$ \\
\hline Apo B & $124+14$ & $138+22$ & 2.5 & $<0.05$ & $\mathrm{~S}$ \\
\hline Apo-B/apo A-1 & $1.03+0.2$ & $1.5+0.7$ & 3.3 & $<0.001$ & $\mathrm{HS}$ \\
\hline
\end{tabular}

S*: Significant. HS**: Highly Siginificant.

This table shows that subjects with metabolic syndrome had higher CIMT, higher apo B, Higher apo-B/ apo A-1 ratio, lower apo-A compared to subjects without metabolic syndrome, with statistically significant difference in between by using unpaired t-test.

Table 8: Correlation between CIMT versus other variables

\begin{tabular}{|l|c|c|}
\hline Variables & $\begin{array}{c}\text { CIMT } \\
\text { r }\end{array}$ & P \\
\hline Age & 0.44 & $<0.05 \mathrm{~S} *$ \\
\hline BMI & 0.18 & $>0.05$ \\
\hline SBP & 0.38 & $<0.05 \mathrm{~S}$ \\
\hline DBP & 0.18 & $>0.05$ \\
\hline Framingham risk score & 0.45 & $<0.001 \mathrm{HS} * *$ \\
\hline SCORE System & 0.46 & $<0.001 \mathrm{HS}$ \\
\hline Number of risks & 0.55 & $<0.001 \mathrm{HS}$ \\
\hline Apo-A1 & -0.34 & $<0.05 \mathrm{~S}$ \\
\hline Apo-B & 0.29 & $<0.05 \mathrm{~S}$ \\
\hline Apo B/A1 & 0.30 & $<0.05 \mathrm{~S}$ \\
\hline hs-CRP & 0.03 & $>0.05$ \\
\hline Microalbuminuria & 0.24 & $<0.05 \mathrm{~S}$ \\
\hline *S: Significant **HS: Highly Significant
\end{tabular}

$*$ S: Significant $* *$ HS: Highly Significant 
This table shows statistically significant positive correlation between carotid intima media thickness (cIMT) versus age, SBP, apo B, apo B/A-1, microalbuminuria and negatively correlated to apo A-1 by using correlation coefficient test. no significant correlation was observed as regard other variables.

Table 9: Significant factors affecting CIMT by linear regression using stepwise technique

\begin{tabular}{|l|c|c|c|}
\hline Variables & Beta-coefficient & $\mathrm{P}$ & $\mathrm{R} 2$ \\
\hline Number of risks & 0.38 & $<0.05$ & 0.56 \\
\hline apo-B/apo A-1 ratio & 0.36 & $<0.05$ & 0.54 \\
\hline Microalbuminuria & 0.35 & $<0.05$ & 0.33 \\
\hline
\end{tabular}

This table shows that the most significant factors associated with cIMT are Number of risks, apo-B/apo A1and Microalbuminuria.

\section{Discussion}

Atherosclerosis is a chronic inflammatory process, developing in response to some metabolic disorders, infections and environmental processes, which initiates and promotes lesion development to the point of acute thrombotic complications and clinical events ${ }^{(17)}$.

The initial lesion in atherosclerosis begins in childhood with the development of fatty streaks. It comprises an endothelial dysfunction as an initial step together with lipid accumulation triggering an inflammatory response. This response is characterized by the production of a wide variety of mediators that include proinflammatory cytokines, chemokines and reactive oxygen species ${ }^{(18)}$. It has been found in some prospective epidemiological studies that the increase in the vascular risk occurs in association with increased basal levels of cytokines such as IL- 6 and TNF $\alpha$, cell adhesion molecules such as soluble ICAM-1, P-selectin E selectin, and downstream acute-phase reactants such as high sensitive C-reactive protein (hsCRP), fibrinogen, and serum amyloid $\mathrm{A}^{[19]}$.

Elevated levels of several inflammatory mediators among apparently healthy men and women have proven to have predictive value for future vascular events ${ }^{(20)}$. For clinical purposes, the most promising inflammatory biomarker appears to be hsCRP, a classical acute-phase marker. In addition to providing downstream integration of overall cytokine activation hsCRP has several direct effects that may affect vascular disease progression. These include an ability to bind and activate complement, induce expression of several cell adhesion molecules as well as tissue factor, mediate LDL uptake by endothelial macrophages, induce monocyte recruitment into the arterial wall, and enhance production of monocyte chemotactic protein 1 (MCP-1) ${ }^{(21)}$

The ultrasound-based measurement of CIMT, has become a standard for assessing arteriosclerosis and is recommended by the American Heart Association for the non-invasive assessment of cardiovascular risks ${ }^{(22)}$.

B-mode ultrasound-based CIMT measurement and carotid plaque detection is one of the surrogate markers of atherosclerosis that has shown value in CHD risk prediction. It has been shown that adding either CIMT, plaque, or both to traditional risk prediction models improves CHD risk prediction. Carotid ultrasound-based CIMT measurement and plaque identification is noninvasive, safe, and relatively inexpensive ${ }^{(23)}$.

The term of "cardiometabolic risk" and "metabolic syndrome" and the process of "risk stratification" overlap \& they are all related to the atherogenic process and the development of type 2 diabetes which is an important cardiovascular risk factor. The term "global cardiometabolic risk" is mainly considering factors that go beyond the set of traditional risk factors and that include new or emerging risk factors such as abdominal obesity, inflammatory profile, oxidative stresses, thrombotic profile and ethnicity ${ }^{(24)}$.

Several studies and clinical trials revealed that, apoB has been found to be a better predictor of 
CVD risk than LDL. These analyses suggest that once LDL cholesterol is lowered, Apo B may be a more effective way to assess residual CVD risk and to determine the need for medication adjustments. However, not all studies agree, in some studies, apo B did not outperform LDL cholesterol and non-HDL cholesterol as risk predictor $^{(25)}$.

Our study included 80 subjects selected from the employee of kasr Al Aini shool of medicine \& they had different risk factors for atherosclerosis. The aim of the work is to study the correlation between apo B, apo A-I and apo B/ apo A-I ratio versus some early markers of atherosclerosis (CIMT, hs-CRP, microalbuminurea).

We applied the Framingham point score system and the SCORE system on Subjects of our study to stratify them into different risk categories (low risk, intermediate risk, high risk, very high risk). Another traditional risk estimation method, which is the number of risk factors prevalent in the subjects of our study was also applied (that ranges from three to ten risk factors).

We noticed that subjects with high and very high risk category according to the SCORE system are stratified as high risk category using Framingham point score and their number of risks ranges from seven to ten risk factors and those subjects account for about $45 \%$ of our study group.

Our study revealed a significant negative correlation between risk estimation systems (Framingham point score system, SCORE system, number of risk factors) and apo A-1 and revealed positive correlation to both apo B \& apo B/apo A1 ratio. This means that as long as there is an increase in the risk scoring systems or the number of risk factors among our subjects, this will be reflected on the total burden of potentially atherogenic lipoprotein particles.

As regard the subjects which fulfilled the criteria of metabolic syndrome there was a significant increase in CIMT, microalbuminurea, apo $\mathrm{B}$, apoB/apo A-1 and significant decrease in apo A-1 and these results were consistent with other studies. ${ }^{(26,27,28)}$.
Our study revealed that there is positive correlation between cIMT and microalbuminurea. This finding is consistent with a study performed by Rodondi et al (2007) on 1255 participants, that revealed that microalbuminurea is associated with carotid atherosclerosis, as assessed by IMT, beyond traditional cardiovascular risk factors among middle aged adults, but not cystatin $\mathrm{C}^{(29)}$.

Also Shin et al (2012) reported that microalbuminurea was strongly associated with arterial stiffness assessed by brachial-ankle pulsewave velocity, CIMT, hsCRP in untreated diabetic or hypertensive patients. Interestingly, in patients with diabetes, the level of microalbuminurea is more highly correlated with arterial stiffness than thickness ${ }^{(30)}$.

Our study revealed that CIMT has a significant positive correlation with apo B and apo B/apo A1 , and has a significant negative correlation with apo A-1.

The most significant factors that correlate positively with CIMT according to our study by using the multivariate linear regression analysis with a stepwise technique are the number of risks, apo B/apoA-1ratio and microalbuminurea and so we can consider that, the number of risk factors might be a better indicator of risk stratification compared to other risk estimation systems for prediction of cIMT as an early marker of atherosclerosis.

Also we can consider the ratio of apoB /apoA-1 as an independent risk factor that seems to be a more useful indicator of risk compared to the absolute figure of either Apo B or Apo A-1 owing to the fact that apoB and Apo A-1 have opposing effects on atherogenic risk, and this is consistent with the findings of a study performed over 309 indian subjects by Jadhav and Kadam that revealed that the increased ApoB: ApoA-1 ratio > 1 was significantly associated with increased IMT even after inclusion of all other traditional risk factors into the model ${ }^{(31)}$.

Many other Prospective clinical trials have reported that apoB and apoA-I are important predictors of CHD risk ${ }^{(32)}$. 
Also the INTERHEART study confirmed that the increased apoB/apoA-I ratio is significantly related to acute myocardial infarction. This association was noted in men and women, old and young, and in all regions of the world. ${ }^{(33)}$

In a multivariate analysis, the concentration of apoB was more highly significant than LDL cholesterol and added predictive power to LDL cholesterol assessment. According to the Copenhagen City Heart Study, the prediction of future ischemic cardiovascular events could also be improved by measuring ApoB alone ${ }^{(34)}$.

Moreover the American association of clinical endocrinologists (AACE, 2012) in its guidelines for the managements of dyslipedemia \& prevention of atherosclerosis recommended performing apo $\mathrm{B}$ measurements to assess the success of LDL-C-lowering therapy. Apo B reflects LDL particle number, which may be elevated in patients at or below LDL-C goal. While LDL-C and LDL particle size (eg, small, dense LDL) are associated with atherogenicity, LDL particle number as reflected by apo B is a more potent measure of cardiovascular disease (CVD) risk. They also recommended the assessment of apo AI which may be useful in certain cases. They stated that a normal apo AI level in a patient with low HDL-C suggests the existence of an adequate number of HDL-C particles that contain less cholesterol and may be an indication of less risk. They also supported the INTERHEART study results that found that the apo $\mathrm{B}$ to apo AI ratio was among the most significant risk factors for MI ${ }^{(35)}$.

Our study revealed no correlation between CIMT and hsCRP, it was concordant with Takebayashi et al who investigated 73 patients with type 2 diabetes, concluded that fibrinogen and hsCRP might be closely associated with diabetic microangiopathy and that both markers did not correlate with IMT as a marker of macroangiopathy ${ }^{(36)}$.

Bo et al (2009) concluded that among asymptomatic moderate-to-high $\mathrm{CV}$ risk subjects, hs-CRP levels were associated with severity of peripheral atherosclerosis, but these associations were not independent of traditional $\mathrm{CV}$ risk factors ${ }^{(37)}$ and Lorenz et al (2007) concluded that hs-CRP was not an independent causal factor for the initiation and progression of early atherosclerotic changes of the carotid arteries ${ }^{(38)}$. Other studies that studied the correlation between hs-CRP levels and the severity of coronary atherosclerosis in patients with CAD remains controversial. Some studies have reported significant associations between hs-CRP levels and the severity of coronary stenosis (39,40), whereas others have not ${ }^{(41,42)}$.

The study revealed that hsCRP is not correlated with any of the lipid profiles (TC, LDL-c, TG and HDL-c) and Apolipoproteins (B, A-I). The lack of correlation between hsCRP and lipid levels is consistent with results from other studies $(43,44,45)$ and this lack of correlation is not consistent with many other studies as Hrira et al (2012), who reported a highly significant positive correlation between apoB and hs-CRP but weaker correlations between hs-CRP and apoAI ${ }^{(17)}$.

We conclude from the results in our study that the use of the number of risk factors to screen the subjects of our research might be a better, easy and simple indicator of risk estimation compared to other risk estimation systems for the prediction of CIMT as an early marker of atherosclerosis. Also, the ratio of apoB /apoA-1 is a strong risk factor that seems to be a more useful indicator of vascular risk. Subjects with metabolic syndrome show significant increase in CIMT, microalbuminurea, apo $\mathrm{B}$, apo B/apo $\mathrm{A}-1$ ratio, and significant decrease in apoA-1.

Due to the significant correlation of apo B, apo A1 and the ratio of apoB/ apo A-1 to CIMT, their routine use as an important marker among the traditional lipid profile is highly recommended.

In addition to that, prospective studies need to be carried out in order to evaluate the association of these biomarkers with subsequent cardiac events to further lend an insight into their usefulness in the diagnosis and prognosis of CAD. 


\section{References}

1. Jaspinder Kaur. A Comprehensive Review on Metabolic Syndrome. Cardiology Research and Practice Volume2014 (2014), Article ID 943162, 21 page.

2. $55 \%$ Gori $\mathrm{T}$, Muxel S, Damaske A, Radmacher MC, Fasola F, 55\%Schaefer S, 55\% Schulz A, 55\%Jabs A, 55\% Parker JD, Münzel T. Endothelial function assessment: flow-mediated dilation and constriction provide different and complementary information on the presence of coronary artery disease. Eur Heart J. 2012 Feb;33(3):363-71. First published online: 14 September 2011

3. Mariarita Dessì, Annalisa Noce, -Pierfrancesco Bertucci, Simone Manca di Villahermosa, Rossella Zenobi, Veronica Castagnola, Eliana Addessi, and Nicola Di Daniele. Atherosclerosis, Dyslipidemia, and Inflammation: The Significant Role of Polyunsaturated Fatty Acids. Vol 2013 (2013), Article ID 191823, 13 pages.

4. Lokhande Suryabhan L, Iyer Chandrashekhar M, Shinde Ratnendra R, Nandedkar Prerna D, Kamble Mahendra T. Prognostic significance of Apolipoprotein B over traditional lipid parameters in atherosclerosis risk management in Type 2 diabetes mellitus. JPBMS, 2012, 21 (16)

5. Koren N, Goldbourt U, Graff E, et al. Apolipoproteins B and AI and the risk of ischemic cerebrovascular events in patients with pre-existing atherothrombotic disease, Journal of the Neurological Sciences 2008 ; $270: 82-87$.

6. Cooney M T, Dudina A and D'Agostino R. Cardiovascular Risk-Estimation Systems in Primary Prevention : Do They Differ? Do They Make a Difference? Can We See the Future? Circulation. 2010;122:300310.

7. Mookadam, F., Moustafa, S. E., Lester, S. J. and Warsame, T. (2010), Subclinical
Atherosclerosis: Evolving Role of Carotid Intima-Media Thickness. Preventive Cardiology, 13: 186-197.

8. Stein JH, Korcarz CE, Hurst RT, Lonn E, Kendall CB, Mohler ER, Najjar SS, Rembold CM, Post WS; American Society of Echocardiography Carotid Intima-Media Thickness Task Force. Use of carotid ultrasound to identify subclinical vascular disease and evaluate cardiovascular disease risk: a consensus statement from the American Society of Echocardiography Carotid Intima-Media Thickness Task Force. Endorsed by the Society for Vascular Medicine. J Am Soc Echocardiogr. $2008 \quad$ Feb;21(2):93-111; quiz 189-90. doi: 10.1016/j.echo.2007.11.011.

9. Lundberg, C., Hansen, T., Ahlström, H., Lind, L., Wikström, J. and Johansson, L. (2014), The relationship between carotid intima-media thickness and global atherosclerosis. Clinical Physiology and Functional Imaging, 34: 457-462. doi: 10.1111/cpf.12116

10. Rodolfo Paoletti,Chiara Bolego, Andrea Poli, and Andrea Cignarella. Metabolic Syndrome, Inflammation and Atherosclerosis Vasc Health Risk Manag. Jun 2006; 2(2): 145-152.

11. Canadian Diabetes Association. clinical practice guidelines Expert committee. Dyslipidemia in adults with diabetes. Can J Diabetes. 2006; 20:230-40.

12. Geuroulakos GO, Gorman D, Nicolaides A, Sheridan D, Elkeler R and Shaper A: Carotid intima-media thickness, correlation with the British regional heart study risk score journal of Int. Med,1994; 235: 431-433.

13. Koracevic D and Koracevic G. J . Clin .Pathol, 2001; 54: 356 - 361.

14. Alberti KG, Eckel RH, Grundy SM, et al. Harmonizing the metabolic syndrome: a joint interim statement of the International 
Diabetes Federation Task Force on Epidemiology and Prevention; National Heart, Lung, and Blood Institute; American Heart Association; World Heart Federation; International Atherosclerosis Society; and International Association for the Study of Obesity. Circulation. 2009;120(16):1640-5.

15. National Cholesterol Education Program (NCEP) .Third Report, Expert Panel on Detection, Evaluation, and Treatment of High Blood Cholesterol in Adults (Adult Treatment Panel III) final report. Circulation. 2002; 106:3143-3421.

16. Conroy RM, Pyorala K, Fitzgerald AP, et al. Estimation of ten-year risk of fatal cardiovascular disease in Europe: the SCORE project. Eur Heart J. 2003;24:987-1003.

17. Hrira M, Kerkenic M, Hamdad BK, et al. Apolipoprotein A-I, apolipoprotein B, high-sensitivity $\mathrm{C}$-reactive protein and severity of coronary artery disease in tunisian population , Cardiovascular Pathology 2012; 21: 455-460.

18. Suvorava T and Kojda G. Reactive oxygen species as cardiovascular mediators: Lessons from endothelial-specific protein overexpression mouse models. Biochim Biophys Acta.2009; 1787(7):802-10.

19. Ridker PM, Hennekens $\mathrm{CH}$, Buring JE, Rifai N. C-reactive protein and other markers of inflammation in the prediction of cardiovascular disease in women. $\mathrm{N}$ Engl J Med 2000; 342: 836-43

20. Libby P, Ridker PM, Maseri A. Inflammation and atherosclerosis. Circulation 2002; 105: 1135-43.

21. Pavel Poredos. Markers of Preclinical Atherosclerosis and their Clinical Relevance.The Open Atherosclerosis \& Thrombosis Journal, 2011, 4, 1-10

22. Rajaram V, Pandhya S, Patel S, et al. Role of surrogate markers in assessing patients with diabetes mellitus and the metabolic syndrome and in evaluating lipid-lowering therapy. Am J Cardiol. 2004; 93(11A): 3248.

23. Smita IN and Nambi V. Current atheroscelerosis reports 2012; 14:115-123.

24. Leiter LA, Fitchett DH, Gilbert RE, et al. Cardiometabolic Risk Working Group: Executive Committee, Identification and management of cardiometabolic risk in Canada: a position paper by the cardiometabolic risk working group (executive summary). Can J Cardiol. 2011;27(2):124-31.

25. Brunzell JD, Davidson M, Furberg CD, et al. Lipoprotein management in patients with cardiometabolic risk: consensus conference report from the American Diabetes Association and the American College of Cardiology Foundation. J Am Coll Cardiol 2008; 51:1512-1524.

26. Palaniappan L, Carnethon $M$ and Fortmann SP.Association between microalbuminuria and the metabolic syndrome: NHANES III. Am J Hypertens. 2003; 16:952-8.

27. Belfki H, Ben Ali S, Bougatef S, et al. The Apolipoprotein $\mathrm{B} /$ Apolipoprotein A 1 ratio in relation to metabolic syndrome and its components in a sample of the Tunisian population. Exp Mol Pathol. 2011 Oct;91(2):622-5.

28. Hartley TA, Shankar A, Fekedulegn D, et al. Metabolic syndrome and carotid intima media thickness in urban police officers. J Occup Environ Med. 2011;53(5):553-61.

29. Rodondi N, Patrick Y, Anne G, et al. Microalbuminuria, but not cystatin $\mathrm{C}$, is associated with carotid atherosclerosis in middle-aged adults Nephrol Dial Transplant 2007; 22: 1107-1114.

30. Shin D, Seung K, Seo S M, et al . clinical assessment of the association between microalbuminuria and predictors of atherosclerosis, JACC , 2012 volume 59, issue 13: 189-485. 
31. Jadhav UM and Kadam NN. Apolipoproteins: Correlation with Carotid Intima-Media Thickness and Coronary Artery Disease Indian Heart J. 2004; 53:370-375.

32. Kampoli A, Tousoulis D, Antoniades C, et al. Biomarkers of premature atherosclerosis ,trends in molecular medicine 2009; Vol.15 No.7 ,223-232

33. Yusuf S, Hawken S, Ounpuu S, et al; INTERHEART Study Investigators. Effect of potentially modifiable risk factors associated with myocardial infarction in 52 countries (the INTERHEART study): case control study. Lancet 2004; 364:937-52.

34. Benn M, Nordestgaard BG, Jensen GB, et al. Improving prediction of ischemic cardiovascular disease in the general population using apolipoprotein B: the Copenhagen City Heart Study. Arterioscler. Thromb. Vasc. Biol.2007; 27: 661670.

35. Paul S. Jellinger; Donald A. Smith; Adi E. Mehta; Om Ganda; Yehuda Handelsma; Helena W. Rodbard; Mark D. Shepherd; John A. Seibel;the AACE Task Force for Management of Dyslipidemia and Prevention of Atherosclerosis. Endocr Pract.2012;18(suppl 1).

36. Takebayashi K, Suetsugu M, Matsutomo $\mathrm{R}$, et al. Correlation of high-sensitivity $\mathrm{C}$ reactive protein and plasma fibrinogen with individual complications in patients with type 2 diabetes. Southern Medical Journal 2006, 99(1):23-27.

37. Bo $M$, Corsinovi L, Brescianini $\mathrm{A}$, et al. High-sensitivity C-reactive protein is not independently associated with peripheral subclinical atherosclerosis. Angiology 2009; 60: 12-20.

38. Lorenz MW, Markus HS, Bots ML, et al. High-sensitivity C-reactive protein is not associated with carotid intima-media progression: the carotid atherosclerosis progression study. Stroke 2007; 38: 17741779.

39. Rifai $\mathrm{N}$, Joubran $\mathrm{R}, \mathrm{Yu} \mathrm{H}$, et al. Inflammatory markers in men with angiographically documented coronary heart disease. Clin Chem 1999; 45:1967-73.

40. Azar RR, Aoun G, Fram DB, et al. Relation of C-reactive protein to extent and severity of coronary narrowing in patients with stable angina pectoris or abnormal exercise tests. Am J Cardiol 2000; 86:205-8.

41. Haverkate F, Thompson SG, Pyke SD, et al. for the European Concerted Action on Thrombosis and Disabilities Angina Pectoris Study Group. Production of Creactive protein and risk of coro-nary events in stable and unstable angina. Lancet 1997; 349:462-6.

42. Zebrack JS, Muhlestein JB, Horne BD, et al. Intermountain Heart Collaboration Study Group. C-reactive protein and angiographic coronary artery disease: independent and additive predictors of risk in sub-jects with angina. $\mathbf{J}$ Am Coll Cardiol 2002; 39: 632-7.

43. Albert MA, Danielson E, Rifai N, et al. Effect of statin therapy on C-reactive protein levels: the pravastatin inflammation/CRP evaluation (PRINCE): a randomized trial and cohort study. J Am Med Assoc 2001;286: 64-70.

44. Jialal I, Stein D, Balis D, et al. Effect of hydroxymethyl glutaryl coenzyme A reductase inhibitor therapy on high sensitive C-reactive protein levels. Circulation 2001; Vol.103: 342-348.

45. Musial J, Undas A, Gajewski P, et al. Anti-inflammatory effects of simvastatin in subjects with hypercholesterolemia. Int J Cardiol 2001; Vol.77, pp.247-53. 